\title{
Social Media during the Egyptian Revolution: Egyptian Nationals at Home and Abroad
}

\author{
MARGOT BUCHANAN, University of Stirling \\ SOHA EL BATRAWY, Cairo University
}

\begin{abstract}
This article considers the significance of social media platforms during the 2011 Egyptian Revolution to two small groups of Egyptian nationals. Interviews were conducted with small groups of Egyptians living in the UK and Egyptians living at home. It establishes how these citizens used social media during the revolution and whether during the days of civil unrest they became citizen journalists by accessing and sharing information and video content with family and friends via digital media platforms such as Facebook and YouTube. This research found that the sharing of online revolutionary content was dependent upon the level of trust with which the interviewees regarded its source. Significantly, interviewees in the UK were reluctant to share any content they received through social media platforms, and trusted only sources that they judged were 'reliable', while interviewees in Egypt shared content that was posted by fellow citizens regardless of whether or not they completely trusted the source.
\end{abstract}

\section{KEYWORDS}

Egyptian Revolution, social media, citizen journalists, trust.

\section{Introduction}

Wael Ghonim, the activist who was able to plan for and initiate the Egyptian Revolution on the 25th of January 2011, stated in an interview with the CNN, "If you want to free a society, just give them internet access" (Ghonim 2011). Nine years earlier Manuel Castells (2002) claimed that the political landscape had been changed by the interactivity offered by the internet. Castells was referring to the new potential of dialogical communication between politicians and voters, but Ghonim was speaking from personal experience after events in Egypt in 2011 illustrated the power of individuals' communication on digital networks to instigate major political change.

The use of social media, especially Facebook, Twitter, YouTube and mobile phone text messages were the main catalyst for this Egyptian Revolution. Social media platforms were the only outlet by which ordinary citizens could vent their anger at events, providing them with a safety valve (Seib 2007) and these platforms played a significant role throughout the revolution. They enabled citizens and activists to share their views of and protests against Hosni Mubarak's regime, which was triggered by the movement "We are all Khaled Saeed", which focused attention on a citizen who was unlawfully tortured and beaten to death by the Egyptian security forces in the Sidi Gaber area of Alexandria on the 6th of June 2010. Ghonim, a marketing manager for Google in the Middle East and North Africa was so angered by that incident that he founded a Facebook page to draw public attention to this tragic incident. This page acted as a hub for news related to the brutality of the Egyptian 
police under Mubarak's regime and eventually led to the Egyptian Revolution. Ghonim was living in Dubai at that time when he called for 100,000 Egyptians to protest in Tahrir Square in the centre of Cairo on the 25th of January 2011. Social media also enabled activists and non-active citizens to video protests and share the footage.

Citizens in Tahrir Square and elsewhere throughout Egypt were empowered by new media, which facilitated a combination of public protests with acts of citizen journalism. They videoed protests and violent police reactions, uploaded them online, and enabled the footage of incidents which took place in Tahrir Square and elsewhere to be publicly accessible. They transformed the Arab media landscape in the process, providing images and footage of events in real time. The Egyptian Revolution in 2011 was enabled by rapid communication that not only facilitated group action, but also the dissemination by private individuals of information about that action to a worldwide audience. This article considers the significance and specific uses of these social media platforms for two small groups of research participants: Egyptian nationals living in the United Kingdom and Egyptian nationals living in Egypt during the revolution.

This article considers whether social media, which enables the flow of information across networks that elide temporal and spatial boundaries, increased the Egyptian users' sense of participation as the levels of social protest rose during the revolution. It further examines how social media were employed by people living in Cairo during the revolt and their families and friends living thousands of miles away in the UK and considers whether these two groups could be considered as practising citizen journalism - the term used to describe the acts of members of the public who disseminate news to other citizens (Rosenberry and St. John III 2010). It seeks answers to the following research questions: what was the role of social media during the revolution for each group? Did it satisfy their need for information and understanding and influence their sense of participation in the revolt? Did they trust social media content as an information source and did they feel a sense of responsibility to disseminate via social media any information they accessed from online sources?

Our findings are based on interviews that were conducted with two groups of Egyptian nationals, one group who lived in the United Kingdom and another composed of Egyptians living in their home country during the revolution. As this is a qualitative study, no large extrapolation can be taken from these research populations; rather its primary focus is to offer an in-depth understanding of the role of social media in these individuals' experiences of the Egyptian Revolution in 2011. As such, the research presents an illustration of the larger picture, rather than offering a comprehensive representation of it (Deacon et al. 1999, 43). As Klaus Bruhn Jensen points out, since it is the "most primary and familiar mode of social interaction' $(2003,240)$ interviewing enables researchers to capture participants' voices, opinions and experiences in their own words; although as he adds, "people do not always say what they think or mean what they say' (ibid.).

Semi-structured interviews were employed with Egyptian citizens who live in their home country and those who lived in the UK at the time of the revolution in 2011. Researchers conducted the interviews with participants living in Egypt using Skype and telephone. As Robert T. Bower notes 'the best way to find out what the people think about something is to ask them' (Bower 1973, cited in Jensen 2003, 240) and by extension and to paraphrase 
Bower, the best way to find out how non-political citizens acted during the revolution is to ask them. To this end semi-structured interviews were selected as they provide both a framework for the questions and the option for the interviewer to ask further questions on points of greater detail. The answers provided by the participants were analysed using critical discourse analysis as it links text and speech acts with the contexts in which they were produced in order to assess similarities and disparities between individuals' responses.

\section{Critical Context}

The potential roles and importance of social media tools in periods of civil unrest has become evident in the past four years; in Iran (in 2009), Tunisia (2011), and Egypt (2011), while its use by Mexican citizens caught up in their country's Drug War has also been noted (MonroyHernandez et al 2012). In North Africa, the increasing significance of digital technologies and social media was highlighted in the uprising in Tunisia in December 2010 following the self-immolation of Mohamed Bouazizi who had been repeatedly beaten by security officers employed by the local council in his home city of Sidi Bouzid. News of the circumstances of his death was disseminated by bloggers and through text messages, generating a network of sympathisers as well as unrest across Tunisia. The members of these networks also shared their grievances about the Tunisian political and media spheres (Howard and Hussain 2012). As Philip N. Howard and Muzammil M. Hussain (2012) note, however, this was a new form of social unrest. Due to the sharing of information and grievances on social media platforms, blogging sites and SMS, the revolt was not organised by one person or group (ibid., 37). As a result, there was no figurehead whom the Tunisian government could identify.

The situation in Egypt was different, however, as Ghonim became recognised as the leading voice of civil unrest in Egypt. The Facebook group 'We are All Khaled Saeed' drew attention to the price Saeed paid for publicising police corruption and, in a situation mirroring that in Tunisia, joined together networks of sympathisers and anti-Mubarak protestors. Ghonim, meanwhile, used Twitter to expose the failings of the Egyptian government and to link Arab- and English-speaking networks around the globe. He also arranged on Facebook for protests to be held on January 25, 2011. The events in Egypt followed a similar pattern to those already experienced in North Africa and beyond, where people who were not political activists used digital media platforms to access information and opinions and to join civil protests. Larry Diamond describes these citizens as "using "liberation technology" (2012, xi); such technologies have "demonstrated potential to empower citizens to confront, contain, and hold accountable authoritarian regimes - and even to liberate societies from autocracy' (ibid.).

Ghonim can be seen to have used digital media very effectively as platforms for protest, a tactic that was quickly adopted by other anti-government protestors. Practical information, such as how to organise a protest, details of organised protests and tales of injustices were shared between social media users on both Egyptian and overseas networks. Social media 'facilitated [...] the dissemination of information and images of protest (and government responses) to the global community via international mass media' (Rane and Salem 2012, 108). Halim Rane and Sumra Salem describe the sharing of information between family and friends on social media as 'proximal' (ibid., 99) as information is disseminated between people who form chains of information and communication with others with whom they 
identify (ibid.) or 'those with whom they share spatial or cultural links' (Rane and Salem 2012, 99).

News and information during the Egyptian Revolution were therefore disseminated by private citizens who assumed the role previously held by professional journalists by sharing their knowledge with a wider audience. As a result, few actions by the Egyptian government went unrecorded by Egyptian citizens equipped with mobile phones. Through social media tools and websites, footage and information were broadcast to Egyptian nationals living in other countries and to overseas mainstream media. These reports were supplied not by Egypt's state-run media, but by the citizens who were protesting in the hub of the civil unrest in Tahrir Square, as well as by the citizens who were attempting to live in the Egyptian capital amid protestors and government security services. These citizens, through their use of social media platforms and text messaging, played a significant role in the dissemination of news about events happening in Egypt. The information shared on social media, therefore, saw non-political citizens acting as citizen journalists, disseminating news from Cairo among themselves, their family and friends living abroad and also, significantly, major news organisations across the globe. Since these citizens' use of social media enabled their audiences to interact, to 'post, comment, debate and argue over shared information' (Ryfe and Mensing 2010, 37), they comply with David M. Ryfe and Donica Mensing's definition of citizens journalists as private citizens for whom interaction based on reports of news events is very important (ibid., p.37). Social media provided 'alternative channels through which information and communications could flow outside the censorship and controls imposed by dictatorships' and worked 'to mobilise people to protest' (Diamond 2012, x). Evgeny Morozov (2011), however, takes a less positive view. What Diamond describes as 'liberation technology' (2012), Morozov labels 'cyber utopianism' (ibid., xiv) and 'internetcentrism' (ibid., xiv), arguing that it is not only the citizenry of countries that are empowered by the Internet, but also authoritarian governments.

There can be no doubt, however, that social media played an influential role in the Egyptian Revolution. Social media is a relatively new term for describing the range of online media platforms which enable groups of individuals to establish personal profiles and to communicate with groups of identified and identifiable friends and acquaintances or with anyone on the Internet. Many of these platforms were originally designated social network sites (SNS), and initially described as websites that enabled participants to

(1) construct a public or semi-public profile within a bounded system;

(2) articulate a list of other users with whom they share a connection; and

(3) view and traverse their list of connections and those made by others within the system (Boyd and Ellison 2007).

Since this definition was offered, however, continuous digital developments have extended the range of services offered by platforms such as Facebook, Twitter and YouTube and broadened their scope from the mainly personal. These social media platforms are now also available on a range of mobile communication devices, a development of great significance in times of civil unrest. Convergence - the process by which content produced for one media platform flows easily across a number of others (Jenkins 2006) - ensures that not only may photographs and videos be taken with mobile phones, but subsequently shared with family and friends on a variety of Internet platforms such as Facebook, Twitter and YouTube. Twitter is a different form of social media from Facebook; users do not share their 
communications on the site (known as Tweets) with a defined audience, but instead re-Tweet messages in a process that develops into a flow of information, described as a 'cascade' by Samuel Solomon (2012). While both Twitter and Facebook enable registered users to upload video content and photographs, YouTube enables a far wider public to upload video content to its website. Each, however, is available on new generations of mobile phones. As a result, mobile phones became the key means of communication and information dissemination during the Egyptian Revolution that was focused primarily on Cairo.

Networks such as Facebook, YouTube and Twitter provide the Web architecture for the social platforms, but rely upon the communication and interaction between their users for their success. While the formation and strengths of relationships on social platforms has been much discussed (see Ellison, Steinfield and Lampe 2007 and Donath and Boyd 2004), there has always been an emphasis on off-line relationships, particularly on platforms such as Facebook (Boyd and Ellison 2007; Ellison et al. 2007; Lievrouw and Livingstone 2010). This social network has enabled close family and friends of Egyptian nationals working in other countries to be kept informed and involved in the lives of those who remain in Egypt, and the link is clear between this previous research and the more recent theory of the proximal diffusion of information put forward by Rane and Salem (2012). The sharing of photographs and video material by protestors in Cairo ensured that while this footage and record of events was directed at family and friends, it could be shared with a far wider audience and be made publicly available to and through the mass media such as newspapers and television. Danah Boyd and Nicole Ellison (2007) argue that social networks offer an electronic means of communicating with existing friends and acquaintances, or of reviving former relationships, rather than as a means of forming new relationships and communities, a further argument that is particularly influential and significant in considering the role of private individuals' communication during the Egyptian Revolution. Equally, however, this argument is challenged by digital technological developments that enabled protestors in Cairo to communicate with a far wider audience than just their circles of off-line friends, while non-political actors in the city could also disseminate information to family and friends living in other countries. This information could include far more detail than might have been recorded in the broadcast media and thus these non-political actors could be seen as acting as citizen journalists. They were not professional journalists, nor did they contribute to citizen journalist websites (Rosenberry and St. John 2010, 32). But much of the information they disseminated to family and friends via social media became available to broadcast media. They informed the public (ibid., 33) as well as their personal networks. They assumed the role of providers of information, and by using social media, enabled interaction with and between those who accessed their news.

These affordances support Castells' (2007) argument that the Internet has led to the development of a new network society, one that is emancipatory because its global, political and social reach expands the horizons available to private individuals. He later argues (2009) that online networks, unrestricted by spatial boundaries, allow individuals to have a voice in the public domain, an argument that is significant in any consideration of the role of social media in the Egyptian Revolution and links to the new forms of communication and interaction that are enabled by digital technologies. The affordances of social media, and the new network society, media convergence and new means of communication together ensured that civil unrest took hold in Egypt in a way that eventually unseated the existing power base, 
making it a prime example of the structuring role played by web technologies as described by Howard and Hussain:

Social discontent can assume organizational form online, and can be translated into workable strategies and goals there as well [...]. [T] his translation process has occurred via mobile phones and social-networking applications even in countries whose governments are very good at coopting or brutally suppressing opposition. (Howard and Hussain 2012, 116)

Clay Shirky (2008) argues that social media, by the way they facilitate the organisation of civil unrest without the need for public meetings, is capable of amplifying certain news and information, and potentially provoking and sustaining political uprisings. 'Once the state does react, the [...] attendees can document and publicize the proceedings, using cameraphones and photo-sharing websites that are much harder to control than traditional media' (ibid., 169). This ensured that the protesters in Cairo could adopt a broadcast communication style to ensure that their voices, protests and their photographic and video evidence of their government's response were available to friends, family and the wider, more amorphous audiences across the globe. Such detailed evidence was therefore accorded a far higher level of visibility than previously experienced by both private individuals and government agencies, as digital media transcended spatial and temporal boundaries. Twitter, Facebook and YouTube provided a valuable link between the protestors in Cairo and the outside world at a time when the Egyptian government was trying to control information about the uprising. Visibility is no longer reliant upon co-presence (Thompson 2005). Such boundless visibility ensured that Egyptian nationals living abroad could view video footage of many of the events in Cairo as they happened or shortly afterwards. Social media also enabled them to share the news and footage with their networks of friends through the provision of links to other websites. While the Egyptian government tried to contain the dissemination of information online about the uprising, their attempts were futile due the affordances of social media. The next part of the article will examine how Egyptian nationals at home and abroad used social media and seeks to establish if they adopted the same approach to content received via social media platforms.

\section{Egyptian Nationals Living in the UK}

Eight Egyptian nationals living in the UK were interviewed to establish their social media practice before and during the revolution, and whether their experience of the revolution via social media platforms encouraged them to feel a greater sense of involvement in the events happening in their home country. Each of the respondents revealed that they use social media platforms every day, a fact that is unsurprising since these platforms enable expatriates the opportunity to keep in close contact with relatives and friends still living in Egypt. Facebook is the most popular social media platform used by every interviewee; the social network's users benefit from the ability to post photographs and links to video footage on other platforms, chat and instantly message friends and family through a single portal. It was not their sole social media platform of choice, however, as each also uses a combination of Skype, Twitter, text messaging and YouTube, although with less frequency.

Sherin (aged 26) used Facebook, and BlackBerry Messenger constantly throughout the revolution to communicate and exchange information. While she has always used Skype and BlackBerry Messenger to communicate with her family, during the revolution she mainly 
used Facebook, her favourite social media platform, and Blackberry Messenger. Sherin said that her social networks were important for satisfying her constant need for information during the revolution, and she feels that they improved her level of understanding of events in Egypt. Immediacy was a major factor in her reliance on social media which 'allowed people to quickly make plans and communicate instantly with large numbers. It allowed people to freely express their opinions', she added. Since the revolution, she uses Facebook as her main source of news about the political situation in Egypt, although she uses Skype as her main way of communicating with her family in Egypt.

Ahmed Galal (39) had previously used Facebook predominantly to communicate with his family and friends in Egypt. During and since the revolution, he has used various social media in order to 'follow the political issues and read my network comments'. Immediacy was also a significant factor in his use of social media during the revolution, a point with which other interviewees agreed. Ahmed commented that 'social media is the fastest way to get information', adding that it also meant that 'you can see how others interact with the news by their comments'. Mohammad El-Maghraby (29) agreed that the immediate access to information on events in Egypt had been significant, but that access to a range of viewpoints had also been particularly important to him as an Egyptian living abroad, an issue that Hany El Zahar (40) described as being a very 'useful feature' of social media during the period of civil unrest. Most of the interviewees agreed that, besides serving as a logistical tool for activist organisation, their use of social media enhanced their understanding of events taking place in Egypt. Tamer (38) described social media as

one of the main sources of information for me. That does not mean that I don't listen to, read or watch the news in other sources. But social media gave me the chance to look at all the news in one place. Facebook users tend to post the most important links to articles or YouTube videos, so by following these links I managed to know the news, i.e. using my Facebook friends as my secretary [sic] who goes through the heaps of info for me.

Dr Ahmed El-Sheikh (50) and Hany also both described how their social media use changed during and after the period of the revolution, becoming more frequent and for longer periods as they sought to keep abreast of developments in Egypt.

\section{Involvement}

Social media encouraged most of the participants to feel a sense of involvement in the revolution, even though they were thousands of miles away. Most agreed that they had a sense of witnessing events as they took place, and were able to discuss events with friends and colleagues in the UK Sherin and her husband became active in Scotland:

My husband and I were actively participating in all the demonstrations held in Dundee in support of the Egyptian Revolution. In the times when most Egyptian TV channels were giving misguiding and false information, including that the world looked down on the [...] Revolution and that it is causing a disgrace to the country, I tried my best to inform my family and friends in Egypt about the contradictory image from the UK and the amount of support we were getting from the Government and the Scottish people.

Her husband gave a public speech about the revolution and featured in their local newspaper. Sherin also felt a sense of responsibility to share information about and links to videos of 
incidents in Egypt with her social network through Facebook as on occasion footage revealed actions by the Egyptian government that contradicted recently broadcast rhetoric. Ahmed attended demonstrations in Glasgow during the revolution, saying that social networks gave him a sense of participation in the events that were taking place in Egypt, by enabling him to actively contribute to events and activities via Facebook. Rania (41) who also felt her use of social media engendered a sense of participation in the events in Egypt, raised funds to send back to her native country. Naglaa (37), meanwhile, took an alternative path to actively supporting the revolution from the UK She used Facebook to enhance awareness of the beauty and culture of Egypt by organising an event through the social network to encourage tourism to her home country, and inviting Facebook Friends to attend. She also decided to 'Like' and 'Share' only positive information about Egypt.

\section{Trust}

Despite feeling involved in the conflict in Egypt while living in the UK through the use of social media platforms, the interviewees did not necessarily feel obliged to share the content they received. While Hany felt a sense of responsibility to share information about videos of incidents in Egypt with his wider network, he had reservations, considering that comments on and videos of incidents were 'biased', a view shared by Mohammad. Hany did not share the information or videos he received with his network of friends and acquaintances, saying 'information has to be from a reliable source'. Mohammed remarked 'one has to be cautious regarding the level of credibility of the news shared through social media [...] not every piece of information given is reliable'. Ahmed shared some information and videos of incidents in Egypt, but not all; he was careful about what he shared, and needed to be sure of the credibility of the sources and incidents. While he shared content with which he agreed, he would 'carefully' watch the videos in their entirety before deciding whether or not to share them. Ahmad commented that without social media, he would have relied on other information sources which he considers to be 'more reliable'.

Naglaa, who felt that social networks did not enable her to feel a sense of participation in events in Egypt, also checked the sources of information she received.

I never took any information for granted unless I trusted the sources. I felt a responsibility to share only the positive aspects of the revolution, especially those that enhance the positive image about the country, information about $[\ldots]$ the unity between the Christians and Muslims during the revolution, when the Christians used to guard the Muslims.

Tamer did not feel any responsibility to share information or videos that he received via social media with his wider social network, and ventured no opinion of the people who commented upon or uploaded videos of incidents. Despite his enthusiasm for receiving information through social media, he felt very strongly that it did not improve his level of understanding of events. He put his faith in professional journalists, such as those working for Aljazeera, who 'get money for doing their jobs accurately and honestly. I also trust some amateurs' videos which were uploaded on Facebook, but ... they were broadcast on all channels so why not trust such videos?' While he did not always trust the reliability of information and links he received on Facebook, he said he trusted his abilities to judge whether or not the material was credible. 


\section{Egyptians Living in Egypt}

Nine Egyptian nationals living at home were interviewed, including Shehenda Maklad the famous Egyptian female activist. The interviews revealed that they were avid users of social media platforms, with the majority of participants accessing networks every day. Again, Facebook was the most popular social network, with YouTube, Skype, Twitter and short message services (SMS) ${ }^{1}$ also used for communication with family and friends. Only May (29), however, said that she had used social media more frequently during the revolution 'to get direct feedback from my family, friends and relatives'. She communicated by private messages on Facebook, writing on other's 'walls', and via SMS. During the time of the revolution, however, she was out of Egypt, in another Gulf country and relied on social media for contacting family and friends at home in Egypt. She remarked that without social media she would have experienced far more difficulty in accessing regular information about the revolution: 'I felt somehow relieved that I was constantly fed with updates and feedback on what was happening in our country. It improved my understanding of events.' Sama (34) said the information she accessed about events via social media was 'very convenient, quick and on the spot'. Reem (26), however, described how she felt nervous and upset when she received information about the revolution through social media platforms. Despite feeling this way, she felt that social media gave her a deeper sense of understanding of events, a point which was agreed by Sherry (31) and Amir (26). Abeer (36) said she 'depended on Facebook during and after the revolution' for information about events, while Marwa (24) uses social media, especially Facebook, Twitter, Skype and YouTube, every day and this did not change during or after the revolution. Despite this, she felt that social networks did not satisfy her need for information about the revolution, although she admits that it did boost her understanding of events. Of the interviewees living in Egypt, only Heba (23) relied primarily on mainstream media, television, for information. She uses social media once a week, preferably Facebook and this did not change during or after the revolution. However, she does not think that any information she received via social channels improved her understanding of the revolution.

\section{Involvement}

Most of the interviewees, including Marwa (24), Reem, May and Sherry, agreed that social media content allowed them to witness events in real time, and to feel a sense of involvement in the revolution. Amir also experienced a sense of witnessing events 'it made me feel more knowledgeable with all that happens [...] on the spot'. He felt that social media made him feel more knowledgeable and gave him a greater degree of understanding and a sense of participating in events during the revolution. He became involved in social media activities that supported the revolution, and physically contributing to and volunteering with 'a group to clean Egypt'. Abeer, also participated physically by volunteering through a Facebook group to give blood in Tahrir Square. Reem and May also experienced a feeling of participation and involvement through their use of social media, with May commenting 'without a doubt, I felt more involved with social media'. Neither Marwa (24) nor Heba, however, felt a greater sense of involvement or participation in the revolution through their use of social media. While Heba considered that social media platforms enabled her and members of her network to witness incidents in real time, she commented 'I would not have felt less involved without social media platforms as I would have depended totally on television and people living beside me'.

\footnotetext{
${ }^{1}$ Short message service "texts "are usually sent from one mobile phone to another.
} 
Many of the interviewees, however, held positive views about the social media content they received and accessed. Amir felt this action indicated that those who uploaded videos and content about the revolution were 'interested in politics' and enabled him to understand their interests and points of views. May also considered that uploading videos and commenting online were truly positive actions: 'I think that that person is taking an active role in the revolution and is playing a vital role in his/her feeling so responsible to be a part of our country's movement'. Sama also considered people who uploaded videos or commented on videos or events online as 'politically active', as these actions became highly visible to others in the same network. Marwa, however, felt that those who posted comments or uploading videos were not necessarily politically active but that the comments and videos helped her to understand their thoughts and beliefs. While Sherry viewed them as being 'positive' people, she added the caveat 'only if he or she shares it with an appropriate attitude'. This suggests a more subjective assessment of the content she accessed and the people who uploaded the content and a lack of recognition of any political implications, in contrast to the political awareness exhibited by Marwa and Sama.

\section{Trust}

The majority of the interviewees felt a duty to disseminate the information they received via social platforms with their wider networks of friends and family despite the fact that they displayed various levels of trust in the content. Heba, who said she did not trust the information she received via social media and that it did not impact upon on her knowledge or understanding of events, said she felt a sense of responsibility to share information about videos of events in Egypt, and that people who uploaded videos or commented on an incident they had heard about played an important role. Sherry, who shared Heba's distrust of the material she received through social media, and Reem, who neither trusted nor distrusted the material, also felt obliged to share the information they received. Their attitudes to those who posted material differed greatly however. Sherry added it was important to share information because it increased the store of knowledge and understanding of events. Reem felt that sharing and commenting on material was a positive action, because of what the action revealed. 'I discovered that some of my friends have narrow minds,' she observed, while Marwa also found comments posted online revelatory since they revealed the beliefs and views of those posting.

Abeer also shared links to videos of events in Egypt with her wider social network through Facebook, on which she relied as she lives in Tahrir Square and was housebound due to protests there for ten days. She trusted 'most videos': 'Amateurs videoed the incidents from different angles and all what [sic] I watch is absolute reality'. She was, however, affected by the comments posted online:

I found that every party was trying to convince me and pull me to its end [...] I was really confused. I found my friends fighting with me if I had a different viewpoint so I stepped back, because I hate being affected by views.

As well as Facebook, Abeer also uses YouTube regularly, and found that the two sites were extremely useful during the revolution because of the way in which they could be used as archives. During days without internet and telephone access, she could later access material that had been uploaded on these days. 'I love YouTube,' she said, 'I watch it [...] to judge for myself on things. I watch - I use my own eyes, my own mind to think, analyse and judge. 
It is a registry.' Only Sama said she felt no sense of duty to share information about events of incidents during the revolution with her wider network, despite the fact that she trusted the information she accessed online

76-year-old activist Shahenda Maklad highlighted the importance of the role played by social media in the revolution. She has been a political activist for over fifty years, fighting for the rights of the poor and underprivileged and sometimes paying the price of imprisonment (Adam 2012). Shahenda attributes the success of the Egyptian Revolution in forcing President Hosni Mubarak out of office to the existence of social media, which she describes as 'an unprecedented amazing technological development'. Social media have empowered young political activists by providing a valuable communication tool. But Shahenda is an active user of digital media too, claiming she can be found either 'on the streets, or on Facebook; these are basically my places and what I am doing all day'. Shahenda regards the steps taken by Mubarak's regime to cut off Egypt's internet connection and mobile phones during the first days of the revolution as proof of the 'amazing power of social media'. These are also a form of 'ammo' she says, since she can store information and record all her communications on social media: 'I am amazingly able to retrieve it at any time, it is a document, it is a proof, it is history [...] it has such a strong effect.' For Shahenda, social media offer ammunition against state forces through the fact that all communication online leave digital traces that can offer proof in support of her actions should she need it.

\section{Discussion}

This research reveals the significance of social media platforms, particularly Facebook, in the provision of information about events in Egypt to those citizens living in both the UK and Egypt. The affordances of digital media to overcome temporal and spatial restraints ensured that they were kept informed of what was happening in real time whether they were living in Cairo or elsewhere in Egypt or abroad. As a result, the majority of interviewees felt a sense of involvement in the revolution through interaction on social media platforms, with many of the expatriates becoming actively involved either physically, through demonstrations, or online through social media platforms.

Our most significant finding was that trust in online material was a substantial issue. The majority of research participants in the UK exhibited distrust of the sources of social media content and awareness that the affordances of social media could be misused. Despite the fact that they depended upon social media platforms for real-time news and information and were grateful for its accessibility, they expressed a high level of caution about the sources which had uploaded the content. They did not accept it without due consideration; many revealed that their attitude to the content was decided by whether they could identify the source and make a judgement on its reliability. A level of distrust in the social media content was also expressed by several of the interviewees living in Egypt but this was not consistent. Sherry, for example, did not trust all the content she received, but trusted the people who posted the information. Shahenda trusted implicitly the information she received and footage she viewed on social media platforms, and praised social media for the power they gave to young political activists, while Abeer trusted both the content and the people who uploaded it to social media platforms because they were 'amateurs'. The fact that one event was filmed by various people, ensuring different angles of the same event, encouraged her to consider the material genuine and trustworthy in contrast to information and communications from the 
Egyptian government. The material uploaded by citizens, however, may have been considered by Egyptians living in the UK as unreliable because the sources could not be verified. As Tamer revealed, he was more confident of the reliability of information provided by professional journalists, while Ahmed also trusted content from 'reliable' sources.

\section{Dissemination}

The issue of trust in social media content influenced the decisions made by Egyptian nationals living in the UK as to whether or not to share the messages and links to other websites with their network of friends. While they welcomed the information they received through social media, only a few trusted it to the extent that they shared it with others. This level of distrust discouraged them from disseminating the content they received to others in their social network. There was more of a divide in the levels of trust in social media content expressed by the interviewees living in Egypt, but despite the trust or distrust with which they viewed the social media content, each of the interviewees living in Egypt felt a great sense of responsibility to share it with their family and friends, their 'proximal' networks and those with whom they identified (Rane and Salem 2012, 99). Acting as citizen journalists, they disseminated the information that they felt those in their online social networks at home and abroad needed to know, while the responses and debates over posts proved to be revealing to some interviewees. The comments made by two of the Egypt-based interviewees, Reem and Marwa, suggest that the long term impact of such interaction on social media platforms in times of political unrest may be worthy of further research.

\section{Conclusion}

The significance of social media during the Egyptian Revolution in 2011 is undisputed since the majority of the interviewees used these digital platforms throughout and after the revolution. Most relied on social media for information; this reliance contrasts, however, with the levels of distrust indicated by interviewees both in the UK and in Egypt. UK-based interviewees relied on social media for information yet did not place their trust in the sources of said information. This distrust therefore resulted in a reluctance to disseminate the content to their proximal networks. In contrast, interviewees in Egypt felt an obligation to disseminate to their personal networks any information and footage they received via social media regardless of whether they trusted its veracity or sources and may be considered as acting a citizen journalists during the revolution. What is significant is the reliance on and willingness to share unofficial content by interviewees based in Egypt, while those based in the UK refused to share content from unknown sources. Significantly, however, interviewees in both the UK and in Egypt exhibited a trust in information provided by established broadcast media platforms, with the exception of those in Egypt itself.

This distinction in the behaviour of the two sets of interviewees may be attributed to the issue of distance. The UK-based interviewees were thousands of miles from the spaces where the revolution was taking place. While they were concerned for their family and friends in Egypt and welcomed news from them, this distance and the availability of a wide range of mainstream media, including Aljazeera (which was barred in Egypt for a period of time) and the $\mathrm{BBC}$, offering news and analysis, ensured they were able to gain a wider understanding of the larger picture. They were not subjected to the level of government propaganda experienced by their family and friends in Egypt. The interview participants based in Egypt, however, experienced a Government-imposed blackout of mainstream media outlets and 
Government propaganda, the deceptiveness of which was exposed by amateur footage posted on social media platforms. They were thus reliant on alternative sources of information, mainly social media, to relay an accurate and comprehensive reflection of events. This shows the powerful impact of social and digital media in enabling citizens to overcome government propaganda and censorship. This research suggests, however, that such social media content, published on social media platforms by fellow citizens and protestors, was not completely trusted by either Egyptians living in the UK or those living in Egypt. This indicates a continuing level of trust and dependency on the broadcast media that is not affected by the increasing use of social media as platforms for citizen journalism.

In 2013, meanwhile, the political situation in Egypt remains unstable. While the revolution unseated Mubarak and led to an election which saw the establishment of a legitimately elected government under President Morsi, a military coup took place in 2013 which unseated the Morsi government. Diamond's 'liberation technologies', while apparently having been utilised successfully in 2011, have not had the long-term impact they appeared to promise. Ghonim's comment, with which we started, appears in 2013 to have been premature, and may be considered an example of Morozov's theory of 'cyber-utopianism' (2011, xiv). At the time of writing, the political situation in Egypt remains in turmoil, suggesting that social media may 'mobilise people to protest' (Diamond 2012, p. x), and overcome spatial and temporal boundaries in the dissemination of information, but that their effects are not necessarily long lasting. 


\section{References}

Adam, R. (2012) 'Shahenda Maklad: The Lifelong Journey to Tahrir Square', Alkhabar English [online]. Accessible at http://english.al-akhbar.com/node/3838. Accessed April 4 2013

Bower, R. T. (1973) Television and the Public, New York: Holt, Rinehart and Winston

Boyd, D. and Ellison, N. B. (2007) 'Social Network Sites: Definition, History, and Scholarship', Journal of Computer Mediated Communication, 13(1), 210-30

Castells, M. (2002) The Internet Galaxy, Oxford: Oxford University Press

Castells, M. (2007) 'Communication, Power and Counter-power in the Network Society', International Journal of Communication, 1, 238-66

Deacon, D., Pickering, M., Golding, P., and Murdock, G. (1999) Researching Communications, London: Hodder Arnold.

Diamond, L. (2012) 'Introduction', in L. Diamond and M. F. Plattner, (eds) Liberation Technology: Social Media and the Struggle for Democracy, Baltimore: John Hopkins University Press, pp. 1-7

Donath, J. and Boyd, D. (2004) 'Public Displays of Connection', BT Technology Journal, 22(4), 71-82. Accessible at www.danah.org/papers/PublicDisplays.pdf . Accessed April 30 2013

Ellison, N.B., Steinfield, C., Lampe, C. (2007) 'The Benefits of Facebook “Friends": Social Capital and College Students' Use of Online Social Network Sites', Journal of ComputerMediated-Communication, 12, 1143-68

Ghonim, W. (2011) 'Internet: Road to Democracy ... Or Elsewhere?' [online]. Accessible at http://www.npr.org/2011/08/15/139640456/internet-road-to-democracy-or-elsewhere. Accessed April 302013

Howard, P. N. and Hussain, M. M. (2011) 'The Role of Digital Media', Journal of Democracy, 22(3), 35-48

Jenkins, H. (2006) Convergence Culture: Where Old and New Media Collide, London: New York University Press

Jensen, K. B. (2003) A Handbook of Media and Communication Research, London: Routledge

Lievrouw, L. A. and Livingstone, S. (eds) (2010) The Handbook of New Media, updated edition, London: Sage.

Monroy-Hernandez, A., Kiciman, E., Boyd, D. and Counts, S. (2012) "Narcotweets": Social Media in Wartime', conference paper, The $6^{\text {th }}$ International Conference on Weblogs and 
Social Media, American Association for Artificial Intelligence, 4 June. Accessible at http://research.microsoft.com/apps/pubs/default.aspx?id=160480. Accessed October 292013

Morozov, E. (2011) The Net Delusion, London: Penguin

Rane, H. and Salem, S. (2012) 'Social Media, Social Movements and the Diffusion of Ideas in the Arab Uprisings', Journal of International Communication, 18(1), 97-111

Ryfe, D. M. and Mensing, D. (2010) 'Citizen Journalism in a Historical Frame', in J. Rosenberry and B. St John III (eds), Public Journalism 2.0: The Promise and Reality of a Citizen Engaged Press, London: Routledge, pp. 32-44

Rosenberry, J. and St John III, B. (eds) (2010) Public Journalism 2.0: The Promise and Reality of a Citizen Engaged Press, London: Routledge

Seib, P. (ed.) (2007) New Media and the New Middle East New York: Palgrave Macmillan

Shirky, C. (2008) Here Comes Everybody: The Power of Organising without Organisations, London: Allen Lane

Solomon, S. (2012) Cascades in Cairo: The Role of Facebook and Twitter in the Egyptian Revolution of 2011, PhD Thesis, Georgetown University. Accessible at http://repository.library.georgetown.edu/bitstream/handle/10822/555728/Cascades $\% 20 \mathrm{in} \% 2$ 0Cairo.pdf? sequence=1. Accessed April 302013.

Thompson, J. B. (2005) 'The New Visibility', Theory Culture and Society, 22, 31-51 